\title{
Eco-Conscious Community Development in Non-Formal Education
}

\author{
Tara Stafford Ocansey and Emmanuel Nuetey Siakwa
}

\begin{abstract}
Youth and Women Empowerment (YOWE), based in Ghana's Eastern Region, is a community-based NGO that has been working since 2000 to support empowerment of vulnerable groups and improve their quality of life through community initiatives, adult learning, and advocacy. In 2018, yowe partnered with the Center for Sustainable Development at Columbia University (CSD) to design and implement a series of training initiatives aiming, through a series of non-formal environmental education sessions, to increase women's skills relevant to eco-friendly livelihoods and to raise community awareness of eco-friendly lifestyle choices. The chapter begins with a discussion of YOWE's programmatic history of weaving eco-conscious practices into their various programs, drawing on literature as well as YowE's own experience to consider the main barriers to facilitating behavioral change amidst a landscape of poverty and lack of access to government services. The chapter continues with an overview of the project partnership with CSD, and a presentation of project findings, looking at changes in lifestyle choices and perceptions of how those choices impact the environment. The chapter close with a discussion of lessons learned and implications for how NG Os can integrate environmental education into various program priorities.
\end{abstract}

\section{Keywords}

environmental education - non-formal education - plastic pollution

\section{Introduction}

Sustainable development is commonly described as "the ability to meet the needs of the present without jeopardizing the ability of future generations to meet their own needs" (Brundtland, 1987). In 2015, global leaders adopted the Sustainable Development Goals (sDGs) to address 17 urgent and intersecting

(C) UNESCO IBE, 2021 DOI: 10.1163/9789004471818_013

This is an open access chapter distributed under the terms of the CC BY 4.o License.

Tara Stafford Ocansey and Emmanuel Nuetey Siakwa - 9789004471818 
sustainable development challenges. Under current neoliberal systems, some SDGs may seem at odds with each other. How can countries reduce poverty (SDG 1) and promote economic growth (SDG 8) while simultaneously reducing wasteful, polluting consumption and production (SDG 12) and cutting carbon emissions (SDG 13) to ensure a sustainable future for all?

One country showing great commitment to the SDGs on the global stage is Ghana, a nation that has enjoyed peaceful constitutional democracy for nearly three decades and that has in recent years seen some of the world's fastest economic growth (Moss \& Majerowicz, 2012). As in many countries, economic growth has heightened consumption levels. Daily solid waste generation in Ghana's capital city increased from 1,800 to 2,200 tons per day between 2004 and 2010 (Oteng-Ababio, 2011). As demands of a growing economy generate increased consumer interest in products and services that add to daily convenience and comfort, Ghana's waste management infrastructure struggles to keep pace, leading to widespread waste mismanagement, in turn contributing to public health crises, economic losses, and global environmental crises, including climate change and proliferation of plastic waste in oceans and waterways (Addaney \& Oppong, 2015).

Strides Ghana has made in environmental policy include the 2017 launch of the National Sanitation Campaign, which aims, among other efforts, to establish a National Sanitation Authority, build a youth brigade to enforce sanitation laws, and establish new recovery sites for recycling. In 2019, Ghana became the world's second country and Africa's first to join the World Economic Forum's Global Plastic Action Partnership (Cann, 2019). President Nana Akufo-Addo is Co-Chair of the SDG Advocates (Sustainable Development Goals Advocates, 2019), and his administration has integrated the SDGs into Ghana's national development plans (United Nations, 2019).

These policies however have been slow to take root and lack much community-level implementation. Many of Ghana's beaches and main roads are strewn with plastic waste, with far-reaching consequences. The World Bank (2012) estimates that Ghana loses $\$ 29$ o million US annually to poor sanitation. During rainy seasons especially, plastic pollution clogs drains, leading to public health crises. The 2014-15 cholera outbreak affected nearly 29,00o Ghanaians (Mireku-Gyimah et al., 2018).

SDG 4.7 calls on us to ensure that by 2030 all learners "acquire the knowledge and skills needed to promote sustainable development, including ... through education for sustainable development and sustainable lifestyles". To help achieve the SDGs, and to contribute to realization of the aims of the National Sanitation Campaign, the Center for Sustainable Development (CSD) partnered with the community-based organization Youth and Women 
Empowerment (YOWE) in Ghana's Eastern Region to raise awareness of the negative impacts of waste mismanagement, and to identify short- and longterm solutions that can also help further other community priorities.

This chapter discusses YowE's history of eco-conscious community development programs, drawing on both literature and YOWE's experience to consider barriers to behavior change amidst a landscape of poverty and lack of access to government services. The chapter continues with an overview of the partnership between YOWE and CSD, and a presentation of initial findings from project research looking at changes in lifestyle choices, perceptions of the environmental impact of those choices, and persistent barriers that may impede changes in lifestyle choices or achievement of more systemic solutions. The chapter closes with a discussion of implications for NGOs and how they can help in meeting the SDGs by integrating environmental education into various program priorities.

\section{Environmental Education and Public Concern in Low-Income Communities}

Whereas integration of education for sustainable development (ESD) and environmental education ( $\mathrm{EE}$ ) in formal education tends to reflect the long view, namely preparing the next generation to make ecologically responsible decisions, promoting ESD and EE in non-formal education has the benefit of directly targeting youth and adults who have agency to effect immediate change in their relationships with their natural environments, with consumer habits, and with decision makers. By holistically blending ecocentricism with anthropocentricism, non-formal ESD and EE programs can address local environmental concerns through the lens of how solutions aimed at reducing negative environmental impacts can also contribute to other community priorities (Nhamo \& Inyang, 2011, pp. 193-194).

Indeed, non-formal education is key to solving problems faced by marginalized populations, typically taking an integrated approach that considers intersecting factors influencing opportunities for improved life chances and well-being within communities, and often including skill-building for sustainable livelihoods (Kotzé, 2012). Non-formal-education programs tend to be flexible and democratic in identifying local problems and solutions, contributing toward participants' increased sense of self-efficacy. Fostering a sense of community within non-formal ESD and EE programs can help promote individuals' identities as environmentalists and sustain pro-environmental behavior (Johnson-Pynn \& Johnson, 2010). 
Designing ESD and EE programs that tap into priority community concerns requires understanding how communities view environmental concerns relative to other social and economic concerns. Research on public perceptions of environmental issues shows that poor communities are often more directly hurt by environmental degradation and tend to have high levels of environmental concern (Dunlap et al., 1993; Hunter et al., 2004). In a survey conducted among 2,500 residents of coastal Ghana, $96 \%$ of respondents shared an opinion concerning their local environment, and $32 \%$ considered environmental concerns of greater importance than such social issues as hunger, crime, and health care (White \& Hunter, 2009, pp. 968-972).

Scholars have argued that while individuals from low-income backgrounds may pay lip service to environmental considerations, concern dissipates when solutions come with economic trade-offs (Inglehart, 1995; Harris, 2006). Addaney and Oppong (2015, pp. 33-34) found that, because of low capacity of the municipal waste management service, $79 \%$ of households in a Ghanaian urban coastal municipality rely on private, paid waste collection services or public dumping. They also found that $46 \%$ of residents had been trained by a community-based organization in waste management, yet mismanaged waste remains prevalent, perhaps showing that environmental benefits may not outweigh economic trade-offs in that community. White and Hunter (2009) found, however, that $70.41 \%$ of respondents agreed that protecting the environment should be prioritized, even at the risk of slowing economic growth (p. 975).

How can local environmental concern be galvanized to push for sustainable development solutions that also address priority social and economic concerns, and challenge underlying economic assumptions? Early sustainability discourse critiquing "capitalism's expansionist logic" has been reconfigured by agents of neoliberalism, who equate understandings of economy with free market capitalism, and who frame capitalism and individual consumer choices as necessary vehicles through which sustainability solutions can be realized (Tulloch \& Neilson, 2014, p. 27). This neoliberal version of sustainability discourse has trickled down to ESD and EE, which typically promote individualist approaches to addressing sustainability challenges without a meaningful critique of underlying economic drivers of environmental and socioeconomic injustices (Pitcher, 2010). Approaches that push beyond the usual bounds and conventions of mainstream education (sometimes termed "transformative, transgressive learning" approaches) that value local knowledge and facilitate critique, reflection, and imagination can help foster critical engagement with systemic causes of, and solutions to, sustainability challenges, and can lead to substantive social change (Lotz-Sisitka et al., 2015). Similarly, scholarship on 
community-based environmental assessments conducted in developing contexts show that engaging marginalized voices in active learning and reflection on local sustainability challenges led to more sustainable lifestyle practices and critical examination of underlying beliefs (Sapling et al., 2011).

One major environmental concern in Ghana is weak waste management. Rapid population growth combined with indiscriminate waste disposal leads to municipalities' falling far short of waste management targets, with Ghana's average national collection rate at $30 \%$. Just $3.9 \%$ of solid waste in Africa is recycled, leading to huge losses of renewable resources and economic opportunities (Addaney \& Oppong, 2015; Oteng-Ababio, 2011). The need for greater access to waste management services has led to establishment of private waste management services, such as that of Zoomlion Ghana Limited in 2006. Zoomlion operates in larger, urban municipalities through public-private contracts to keep public spaces clean and has become an ever-larger presence in Ghana and other African countries, creating over 85,000 jobs (Zoomlion, 2020). Households that can afford it can pay for private pickup, while lower-income areas are left to their own devices.

While Zoomlion has become a familiar presence in Ghana's urban and peri-urban areas, need far outweighs combined public and private sector capacity. Participants in CSD and YOWE's Eco Lifestyles program describe their appreciation for the service, but also concern over service inconsistency and limited reach, with one participant explaining, "Zoomlion ... worked seriously, ... sweeping the roads, the markets, ... but now those people are no longer there", while another explained, "The government ... put in place Zoomlion, but for now, the work is totally down". Others expressed concern that the service offers a convenient excuse for litterers. As one person explained, "Somebody will throw things around. You tell them, and the person will say, 'Oh, Zoomlion will come and collect it'. And these things will pile up for days and can even lead to sicknesses".

These gaps in availability and accessibility of waste management services are but one area that integrated, "transgressive" ESD and EE approaches can help address while also addressing economic and health priorities. The International Labor Organization has begun promoting socially-just transitions to green jobs, defined as jobs that generate goods or services that benefit the environment, or involve environmentally friendly processes, with social protections and healthy conditions for workers (van der Ree, 2019). The African Union's Continental Education Strategy for Africa (CESA) includes expanding technical and vocational training (TVET) opportunities as a strategic objective for contributing to economic growth and social equality. As Tikly (2019) notes, revitalizing TVET and providing adult literacy programs, including through the 
informal sector, both help enable sustainable livelihoods and gender equality, and are key to achieving environmental and social justice. Ghana's Council for Technical and Vocational Training (СоTVET) adopted a five-year strategic plan in 2018 to better align TVET programs managed by various ministries and NGOs, many of which operate with outdated curriculums and infrastructure, and have historically low women's participation rates. The strategic plan includes an environmental sustainability strategy for integrating a greening philosophy into curriculums, workplace practices, and communities (Ministry of Education, 2020). How can NGOs help demonstrate how TVET programs can integrate transgressive ESD and EE to promote transitions to sustainable livelihoods and green, just economies?

YoWE's History of Eco-Conscious Education and Development Programming

YOWE, based in the town of Odumase in Ghana's Lower Manya Krobo District, is a community-based NGO that builds capacities of women, youth, and other socially excluded and vulnerable groups toward improved living standards and livelihoods, thereby reducing poverty and deprivation within YowE's operational areas. Since its incorporation in 2002, YOWE has been conscious of ways that concerns about the environment and about sanitation intertwine with goals of alleviating poverty and improving well-being, and it has designed what can be called "eco-conscious" programs accordingly, promoting this intersectional understanding of key community development priorities through their non-formal-education approaches.

YOWE's earliest work included facilitation of adult literacy programs using the REFLECT method (Archer \& Cottingham, 1996), based on Paulo Freire's theoretical framework that asserts that the role of community-based education by and for marginalized peoples is to build in them critical consciousness of the roots of systemic oppression in order for them to empower themselves and organize for transformative change (Freire, 1970). Community-based REFLECT circles provide democratic space in which adult learners participate in facilitated discussions about community issues, and use "participatory rural appraisal" (PRA) approaches to develop action points and plans for addressing them. PRA activities are used to teach basic literacy and numeracy by connecting skills to everyday scenarios; building participants' reading and writing skills along with community mapping, needs identification and prioritization; and lobbying. These activities empower participants to record their daily experiences and advocate for their communities (see Figure 12.1). 
During YOWE'S REFLECT activities, participants - about 9o\% women and $10 \%$ men, all without formal education - identified pressing community needs for diversified income-generating opportunities. YOWE responded with projects for eco-conscious livelihoods. One example is yowE's beekeeping and biodiversity conservation project. Youth from subsistence farming families were equipped with skills to effectively manage a small enterprise, while also preserving the area's biodiversity. Apiaries were established in 6o project communities, raising awareness of the importance of biodiversity while providing over 500 jobs and reducing rural poverty without damaging habitats. Project participants attributed higher crop yields to increased bee pollination resulting from the project.

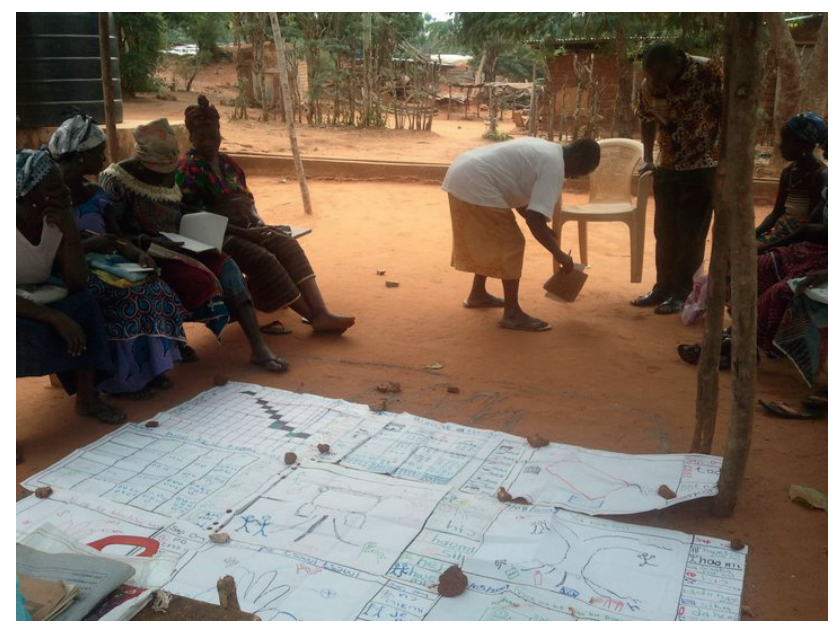

FIGURE 12.1 A REFLECT Circle using PRA tools in 2011, discussing their community action plans

Another major challenge identified over the years is that of inadequate sanitation facilities and poor waste management. YOWE has sought to address this challenge through actions such as community clean-ups and rural-appraisal activities such as social dramas, designed to inspire healthier sanitation practices by building awareness of how certain sanitation and hygiene practices can reduce common ailments, including malaria, tuberculosis, diarrhea, and bilharzia.

YOWE organizes greater engagement between officials ("duty bearers") and constituents through town halls, community engagements, and other meetings ("durbars") to facilitate advocacy pushing the government to address identified challenges. REFLECT communities have engaged with Upper and Lower Manya Krobo district assemblies and traditional authorities to deal with 
the menace of poor sanitation and waste management. This interaction has contributed to district assemblies' partnering with Zoomlion for waste management at public places like market centers and main roads, and to district assemblies' ensuring that every new residential building plan for toilet facilities before they grant building permits. Sanitation days have been established for community cleaning exercises. Even with these forward steps, however, municipal assemblies still often lack the technical and financial resources needed to appropriately respond to growing quantities of generated waste (Addaney \& Oppong, 2015, p. 30).

\section{Eco Lifestyles Program: Implementation and Preliminary Findings}

\subsection{Understanding the Local Context}

A 2019 baseline survey conducted with a small sample of community members in Odumase to inform design of YowE's Eco Lifestyles program found respondents unanimously concerned about the environment and all willing to learn new approaches and to change behaviors to benefit their local environment. Most also agreed that environmental stewardship is everyone's responsibility (90\%), and that government should pass stricter environmental policies $(95 \%)$. When questions got more specific about particular actions to curb waste generation, however, results were more mixed. Of the respondents, $75 \%$ agreed that bringing their own shopping bag was too inconvenient, $6 \circ \%$ agreed that waste separation was confusing, $45 \%$ didn't consider environmental impact in their work or day-to-day activities, and $65 \%$ valued the convenience of plastic and wanted to continue using it. When respondents considered perceived economic trade-offs, results were also mixed. While $85 \%$ were willing to spend more to buy more eco-friendly product alternatives, $65 \%$ agreed that stricter environmental policies would make it harder for people to earn a living.

When asked about household waste management practices, $70 \%$ reported using a trash collection service. Among those not using the service, $6 \circ \%$ reported as the main reason lack of available service in their area, while another $20 \%$ reported infrequent service. To manage their waste, $55 \%$ reported burning it, while $30 \%$ dump it in an open space or nearby dump site. When asked about the prevalence of open burning and dumping, $50 \%$ reported open burning and $70 \%$ reported open dumping to be common.

One major source of Ghana's plastic waste is sachet water, with $50 \%$ of survey respondents reporting sachet water as their primary clean drinking water source. (Sachet water is especially pure drinking water packaged in heat-sealed clear polythene bags of $500 \mathrm{ml}$ or roughly one pint.) Seventy-five percent reported that presence of plastic waste was common in their community. 


\subsection{Program Design and Implementation}

To raise awareness of the harmful effects of mismanaged waste and to identify community-driven solutions, Columbia's Center for Sustainable Development partnered with YOWE to implement a community-based non-formal ESD and EE program, coupled with vocational training for young women to manufacture "upcycled" products from glass and plastic waste. The sensitization part of the program was designed to share scientific information on the health risks of indiscriminate waste management practices, such as open burning and dumping. Workshop activities, including small group discussion and group walks, supplied opportunities to identify waste-related problems and to brainstorm potential solutions. Sessions provided policy background on Ghana's recently launched National Sanitation Campaign as a framework for holding leaders accountable and advocating for additional support. Data was collected over the course of the program through surveys, focus group discussions, and individual interviews. Research questions included the following:

- What messages resonate most with learners to influence their behaviors?

- How do learners negotiate lifestyle changes in their homes and communities?

- How can different vocational areas be leveraged to model alignment between environmental sustainability and economic opportunity within the cultural context?

- How do different approaches to infusing concepts of environmental sustainability into vocational and life skills training lead to changes in learners' behavior and livelihoods?

Leading up to the sensitization program, a group of 15 young women began training in artisan skills for upcycling waste materials into useful products. This aspect of the project represented an immediate local solution, while sensitization and advocacy aspects of the program push for longer-term, systemic solutions. YOWE reached potential applicants via announcements and postings in community centers and churches and on the radio. The yowE board of directors selected applicants on the basis of demonstrated need and commitment to program goals. Some trainees learned skills of recycled glass-blowing (see ConnectToLearn, 2019), while others learned tailoring skills to produce useful everyday products lined with upcycled, waterproofing plastic sachet waste. (Sachets are a type of small, single-use, "single-serving" plastic packaging used for common, low-cost consumer products and popular for their affordability.) The trainees made baby bibs, lunchboxes, pencil cases, toiletry bags, shower curtains, and more. Participants practice entrepreneurship skills through financial literacy and digital skills training for administration and marketing. By linking environmental sensitization with training to support 


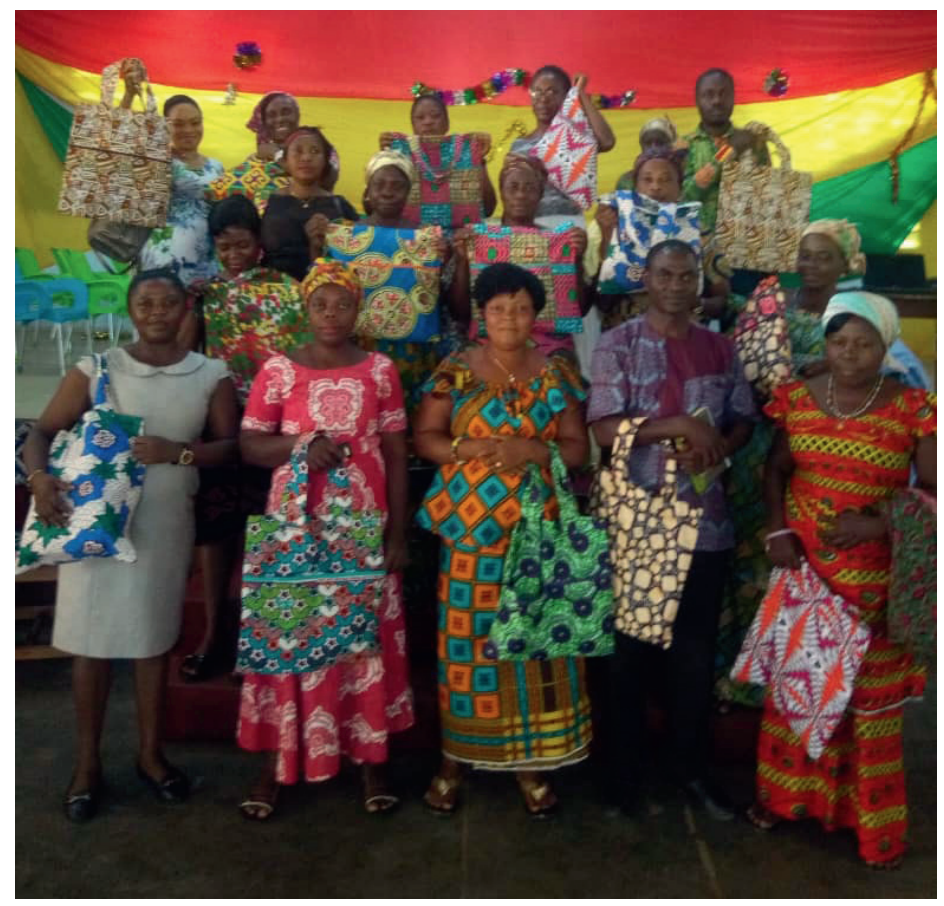

FIGURE 12.2 Workshop participants pose with their new waterproof tote bags made with upcycled plastic sachet waste, distributed to support bring-your-own-bag practice, December 2019

young women's livelihoods, the project demonstrated how being "eco-friendly" means improving both eco-logical and eco-nomic well-being.

Between November 2019 and January 2020, four workshops engaged different community groups of 25 to 39 participants each. Invited community members included Queen Mothers (traditional women leaders), small business owners, market vendors, teachers, Muslim women, and religious leaders. Vocational training participants produced reusable tote bags and distributed them to workshop participants to help them start a bring-your-own-bag shopping practice (see Figures 12.2 and 12.3). Vocational trainees thus became ambassadors of the sensitization work, building their leadership to advocate for longer-term, systemic solutions.

Through facilitated group discussions, participants discussed specific challenges stemming from mismanaged waste, such as how plastic waste chokes drains and leads to health problems with malaria and other diseases, while home burning can lead to respiratory issues, all leading to higher medical costs. Participants identified factors contributing to these problems, such as population growth; increased reliance on single-use plastic for packaging everyday products like drinking water because of lack of access to clean 


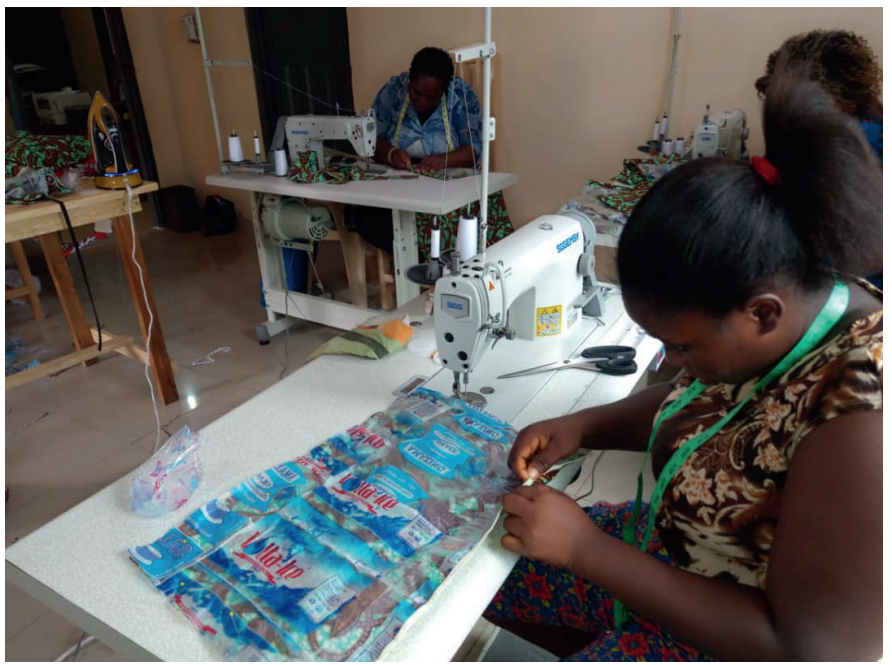

FIGURE 12.3 A vocational training participant prepares a sheet of upcycled plastic sachets to line a tote bag

drinking water from home taps; and lack of waste receptacles in high-traffic community spaces and homes. One participant described common challenges this way:

If it rains, the gutters that are choked already, we also try to put our trash in there. We don't put them in the dustbin .... And that becomes a problem for us .... It breeds mosquitos, and it brings us malaria. So we go to the hospital, and it becomes another expense for us.

Another participant explained, "Education is on the low side. We are not educating ourselves enough to make the environment more friendly, and there are no ... dustbins being put in vantage points".

Workshop groups identified such solutions as talking to family and neighbors about potential benefits of separating waste and recycling; using organic kitchen compost to improve gardens; and turning waste into useful products. Participants discussed how civil society could join with government to provide more waste receptacles and training on how to sustainably maximize benefits from different kinds of recycled waste, including through development of a more robust recycling industry. One participant described the needs:

We must intensify the education by visiting schools, churches .... And also we need to put in the dustbins, where you move two or three meters and you drop in your waste, and it's being carried away by the waste management company. 
Another noted, "We do not have the recycling machines or industry to process these into more usable products, causing this to continue".

One Yowe trainer described workshop participation:

They were complaining about plastic choking the gutters, and people's homes ... getting flooded. So they embraced it. What we came up with was that we would go to the schools and come up with an award scheme in the community. Those who are able to gather a lot and keep their homes and environments clean, we will award them with our products.

YOWE provides ongoing support through WhatsApp groups to follow up with participants on their waste segregation practices and dissemination of key messages within their communities. Participants use these groups to ask questions and motivate each other. YOWE is working with local radio stations to spread these messages further.

\subsection{Program Findings}

Six months after the initial workshops, select participants were asked to participate in focus groups or individual interviews to discuss their views on their environment and everyday waste management practices so that YOWE could see what messages had resonated and how successful participants had been in starting to implement strategies and use knowledge gained during the workshops. Most participant responses demonstrated the resonance of messages connecting a clean environment to improved health. One explained:

We used to burn [polythene] bags after using them. We gather them, and we burn them. But I've come to realize that there are toxins in the smoke ... which is very dangerous to our system .... I was able to convince some part, at least two people in the house, that this time around they are no longer burning [polythene] bags. They have their container where they keep them, and they just send them off to the Zoomlion people.

This example not only demonstrates understanding of the dangerous implications of home burning, but also shows that further sensitization is needed to get to the root problem of reliance on single-use plastics.

Vocational training participants spoke proudly of their work, attributing much of their motivation for separating waste and recycling to financial incentives. Some also pointed to the need for greater government intervention. One trainee explained: 
Most of us in the community, we make sure we do well - that anything that we don't use anymore, we gather it so the government will make up its mind, so they will collect all of them and recycle. And I want the plastic sachets, now that I have experience; so we recycle them. We use it to make many things, like shower caps, lined handbags, raincoats, table mats, many things.

Another explained, "I've seen that this pure water bag, we can use it to do other things, and through those things, we have many benefits. A lot of money is coming out of it". These responses point to the resonance of messages highlighting economic benefits that can come from waste segregation practices, with participants collecting plastic waste from their homes and neighbors.

Another participant explained that he applies what he learned to his work as a teacher

by inculcating the knowledge into the student, how to manage waste, how to reduce the bringing home of polythene bags .... Sometimes you see students always come to school buying food in rubber bags, take-away, and those things, which are waste. You see them dumping everywhere on the compound. So I think ... [of] educating the children, at least how to use flask or bowl ... from the house, so that when they come, they eat from the bowl or flask, you wash it nicely, you send it home, the next day you bring it. Rather than buy a polythene bag that you just put anywhere.

These initial focus group and interview discussions demonstrate that the waste management strategies discussed during the first round of workshops effected some change in participant behavior and shed some light on how messages emphasizing health and economic benefits of more eco-friendly waste management and lifestyle choices can lead to sustained behavior change. However, the responses also demonstrate the need to continue sensitizing participants to long-term, systemic solutions, while also equipping them with skills to continue developing new eco-friendly products and services, as longterm solutions would eventually reduce the market prevalence of single-use plastics.

The Eco Lifestyles program experience, taking into account also YOWE's history of eco-conscious community development initiatives, offers key insights 
into the necessary ingredients of effective community-based, NGO-led initiatives aimed at promoting more sustainable, environmentally friendly systems and practices within communities.

The Eco Lifestyles program was designed to frame the need for protecting the environment through the lenses of high priority issues that may feel more tangible in the everyday lives of people in order to motivate eco-friendly lifestyle choices, such as waste segregation and bring-your-own. Participant responses indicate that these messages on individualized solutions resonated, and participants have spread these lessons to their families and communities. YOWE aims to sustain and deepen this progress with continual education and monitoring.

YOWE's approach combines action at the individual and community levels to help equip citizens with skills and materials to make changes in their lives and communities, along with encouraging group advocacy to push local decision makers for longer-term, systemic solutions. To enhance the effectiveness of their local advocacy, during the workshops, through the weaving in of waste management policy frameworks, participants become informed on key points. Some respondents in interviews and focus groups discussed systemic solutions, such as government enforcement of laws discouraging littering, and constructing more recycling facilities. Nearly all interview and focus group respondents also hammered away on the need for government to provide waste receptacles in homes and public spaces, while also noting that to get it done, civil society should contribute. As one participant explained, "It is the responsibility of the government, or even stakeholders: civil society organizations can take it upon themselves .... When you collaborate, these things can be done". Yowe is committed to supporting the community's ongoing efforts to reduce waste and to support waste segregation practice by helping to distribute waste bins to institutions and urban households. YOWE is also using a common social media platform for participants to coordinate and share ideas.

One lesson yowE considered when designing the Eco Lifestyles program was the need to target programs to young people. Earlier REFLECT projects tended to engage older adults and therefore missed out on the vibrant energy that young people can leverage to effect change. As described by some program participants, there is a perception that young people are often the perpetrators of littering. As one participant explained:

The population has increased ... You go to town, and young ones will go and drink, and then they will drop it all over the place, just like that. If someone complains, they don't listen, because they think they know better. They believe they are taking care of their own self; so if someone says it, they don't listen to the person. In the olden days it was not like that. 
YOWE also engaged a population more urban than rural, with both staff and participants having witnessed the increasing severity of the impact in their urban setting. Ideas raised by participating teachers in the sensitization program are shaping YowE's next steps: extending sensitization to local primary schools through storytelling and discussion activities and provision of waste segregation bins and training. Teachers can empower young students to be ambassadors of community sustainability solutions by identifying where in the curriculum local environmental topics can be discussed, such as using language lessons to develop persuasive messages about sustainability solutions, and teaching math and science concepts through community research projects.

Some participants discussed the need for more youth jobs to help give structure and meaning to young people's lives and to create incentives for practicing responsible waste management. One participant described her ambition to educate young people: “I want us to gather the youth who don't have jobs and are just roaming about. Our community, we don't have good jobs, and I believe that recycling will help us". Program approaches that address environmental concerns while also developing youth leaders and peer mentorship, creating jobs, and improving health may be effective in fostering mindset and behavior changes in young people.

While participants spoke highly of the economic benefits of recycling and waste segregation, programs aimed at pushing for systemic solutions as well as individual behavior change and economic empowerment should take care to help learners focus on long-term, systemic solutions by equipping them with advocacy and entrepreneurship skills that help drive changes toward a more equitable, green economy. Participants who are excited about the current economic benefits of making products by upcycling certain waste materials should hope that long-term solutions might eventually reduce availability of those waste materials. For example, making clean drinking water available and accessible via home taps would lessen the need for sachet water. Non-formal ESD and EE programs must be forthright in discussing these tensions between immediate, "band-aid" solutions that reduce poverty while minimizing negative impacts of waste mismanagement, and the reality that these immediate solutions still feed off an unsustainable system. In the case of the Eco Lifestyles project, participants who were initially more excited about generating products and earning income from waste materials began to increasingly appreciate the need to push for government action to improve waste management and access to clean water and sanitation facilities. The sensitization program deepened their understanding of these intersecting issues - health, economic development, and environmental sustainability. 
The Sustainable Development Goals place the impetus on public, private, and civil society actors to rethink how they can leverage existing resources to address interlinked sustainable development challenges in integrated ways. Ghana has begun heeding this call by embedding a greening philosophy within formal technical and vocational training institutions. YOWE's work extends this approach to the non-formal sector, using short-term training in eco-friendly livelihoods to hook participants into deeper involvement in organizing and advocating for systemic solutions. YOWE's approaches to non-formal education - equipping youth and adults with basic literacy skills along with knowledge of their constitutional rights to inclusive governance and key policy frameworks - can help facilitate these systemic shifts.

By addressing the interlinked sustainable development challenges of waste management, public health, and access to jobs and entrepreneurship support, the Eco Lifestyles program has demonstrated that participants adopt new lifestyle habits that they describe as benefiting their lives in various ways, while also demonstrating that participants desire longer-term solutions, including a more robust, publicly-funded waste management industry, and increased access to skill-building opportunities that lead to improved livelihoods through green jobs. Much of this work hinged on the creativity of yowe trainers in developing useful products made with waste materials that tap into community needs and tastes, and on YOwE's deep history of facilitating democratic adult education and grassroots advocacy with district-level decision makers. This kind of multi-pronged education for sustainable development and environmental education programming is key in leveraging short-term solutions that address immediate poverty and health concerns to galvanize communities to push for equitable, green economies.

\section{References}

Addaney, M., \& Oppong, R. A. (2015). Critical issues of municipal solid waste management in Ghana. Journal of Energy and Natural Resource Management, 2(1), 30-36. https://www.researchgate.net/publication/309392574

Archer, D., \& Cottingham, S. (1996). Action research report on REFLECT: Regenerated Freirean literacy through empowering community techniques: The experiences of three REFLECT pilot projects in Uganda, Bangladesh, El Salvador. Overseas Development Administration. https://eric.ed.gov/?id=ED399393 
Brundtland, G. (1987). Report of the World Commission on Environment and Development: Our common future (United Nations General Assembly A/42/427). United Nations. https://sustainabledevelopment.un.org/content/documents/5987ourcommon-future.pdf

Cann, O. (2019). Ghana becomes first African nation to join ambitious partnership to end plastic pollution. World Economic Forum. https://www.weforum.org/press/2019/ 10/ghana-becomes-first-african-nation-to-join-ambitious-partnership-to-endplastic-pollution/

ConnectToLearn. (2019). Ghana's women glassblowers (YouTube video). https://youtu.be/Tcoo-ApfmjU

Dunlap, R. E., Gallup, G., \& Gallup, A. M. (1993). Of global concern: Results of the health of the planet survey. Environment, 35(7), 333-339. https://doi.org/10.108o/ oo139157.1993.9929122

Freire, P. (1970). Pedagogy of the oppressed. Continuum.

Hunter, L. M., Hatch, A., \& Johnson, A. (2004). Cross-national gender variation in environmental behaviors. Social Science Quarterly, 85(3), 677-694. https://doi.org/ 10.1111/j.0038-4941.2004.00239.x

Inglehart, R. (1995). Public support for environmental protection: Objective problems and subjective values in 43 societies. Political Science and Politics, 28(1), 57-72. https://doi.org/10.2307/420583

Johnson-Pynn, J., \& Johnson, L. (2010). Exploring environmental education for East African youth: Do program contexts matter? Children, Youth and Environments, 2o(1), 123-151. https://doi.org/10.7721/chilyoutenvi.20.1.0123

Kotzé, D. A. (2012). The impact of non-formal education on skills and knowledge of community development workers: A case study. Africa Development, 37(2), 1-14. https://www.jstor.org/stable/10.2307/afrdevafrdev.37.2.1

Lotz-Sisitka, H., Wals, A. E., Kronlid, D., \& McGarry, D. (2015). Transformative, transgressive social learning: Rethinking higher education pedagogy in times of systemic global dysfunction. Current Opinion in Environmental Sustainability, 16, 73-80. https://doi.org/10.1016/j.cosust.2015.07.018

Ministry of Education, Republic of Ghana. (2020). The technical, vocational and skill training. moe.gov.gh/index.php/tvet

Mireku-Gyimah, N., Apanga, P. A., \& Awoonor-Williams, J. K. (2018). Cyclical cholera outbreaks in Ghana: Filth, not myth. Infectious Diseases of Poverty, 7(51). https://doi.org/10.1186/s40249-018-0436-1

Moss, T., \& Majerowicz, S. (2012). No longer poor: Ghana's new income status and implications of graduation from IDA. Center for Global Development. https://www.cgdev.org/sites/default/files/1426321_file_Moss_Majerowicz_Ghana_ FINAL_o.pdf 
Nhamo, G., \& Inyang, E. (2011) Promotion of formal and non-formal environmental education. In G. Nhamo \& E. Inyang (Eds.), Framework and tools for environmental management in Africa (pp. 187-208). CODESRIA. https://www.jstor.org/action/ doBasicSearch?Query=Promotion+of+formal+and+non-formal+environmental+ education

Oteng-Ababio, M. (2011). Missing links in solid waste management in the Greater Accra Metropolitan Area in Ghana. GeoJournal, 75(5), 551-56o. https://doi.org/10.10o7/. s10708-010-9363-9

Pitcher, B. (2011). Radical subjects after hegemony. Subjectivity, 4, 87-102. https://doi.org/10.1057/sub.2010.26

Sapling, H., Montes, J., \& Sinclair, J. (2011). Best practices for promoting participation and learning for sustainability: Lessons from community-based environmental assessment in Kenya and Tanzania. Journal of Environmental Assessment Policy and Management, 13(3), 343-366. https://www.jstor.org/stable/10.2307/ enviassepolimana.13.3.343

Sustainable Development Goals Advocates. (2019). Sustainable development goals advocates: 2019-2020. United Nations. https://www.unsdgadvocates.org/members

Tikly, L. (2019). Education for sustainable development in the postcolonial world: Towards a transformative agenda. In I. Clemens, S. Hornberg, \& M. Rieckmann (Eds.), Bildung und Erziehung im Kontext globaler Transformationen (pp. 17-78). Verlag Barbara Budrich. https://doi.org/10.2307/j.ctvm201r8.5

Tulloch, L., \& Neilson, D. (2014). The neoliberalisation of sustainability. Citizenship, Social and Economics Education, 13(1), 26-38. https://doi.org/10.2304/ csee.2014.13.1.26

United Nations. (2019). UN sustainable development goals knowledge platform: Ghana. https://sustainabledevelopment.un.org/memberstates/ghana

Van der Ree, K. (2019). Promoting green jobs: Decent work in the transition to low-carbon, green economies. In C. Gironde \& G. Carbonnier (Eds.), The ILO@100:Addressing the past and future of work and social protection (pp. 248-272). Brill. https://doi.org/10.1163/9789004399013_o13

White, M., \& Hunter, L. (2009). Public perception of environmental issues in a developing setting: Environmental concern in coastal Ghana. Social Science Quarterly, 9o(4), 968-972. http://www.jstor.com/stable/42940650

World Bank. (2012, April 17). Poor sanitation costs Ghana GHC42O million each year. https://www.worldbank.org/en/news/press-release/2012/04/17/poor-sanitationcosts-ghana-ghc420-million-each-year

Zoomlion Ghana. (2020). About Zoomlion Ghana. https://zoomlionghana.com/aboutzoomlion-ghana 